\title{
Revisitando el concepto de estado en Carl Schmitt. Legalidad, legitimidad y derecho
}

\section{Revisiting the concept of state in Carl Schmitt. Legality, legitimacy and law}

\author{
DOI: https://doi.org/10.17981/juridcuc.16.1.2020.01
}

Artículo de Revisión. Fecha de Recepción: 24/10/2019. Fecha de Aceptación: 20/11/2019

\author{
Ricardo Sebastián Piana \\ Universidad del Salvador (Argentina) \\ rspiana@usal.edu.ar
}

Para citar este artículo:

Piana, R. (2020). Revisitando el concepto de estado en Carl Schmitt. Legalidad, legitimidad y derecho. JURÍDICAS CUC, 16(1). 9-38. DOI: http://dx.doi.org/10.17981/juridcuc.16.1.2020.01

\section{Resumen}

Trabajaremos en el presente artículo los tipos de Estado y sus legitimidades en las obras del jurista alemán Carl Schmitt, evitando caer en una lectura fragmentaria o cargada de prejuicios ideológicos. Se revistarán los textos, realizará una selección y presentarán las principales posiciones sustentadas por el autor, siguiendo su propia exposición. La antología irá acompañada de una exégesis del concepto de Estado, sus distintos tipos y presupuestos. Como principal resultado, advertiremos el problema de la legitimidad en el Estado moderno y su vinculación con lo político, que el liberalismo pretendía soslayar con la equiparación con el criterio de legalidad. Schmitt afirma, por el contrario, que legalidad y legitimidad podían ser, incluso, contradictorios y por ello se referencian los tipos de Estado legislativo, el jurisdiccional y el administrativo y gubernativo. Por último, se confronta el concepto de Derecho, ley y democracia. La tesis de Schmitt demuestra las contradicciones que existe entre el principio de soberanía popular y los controles fijados al sistema parlamentario. Los problemas que señala no han sido superados ni por los actuales modelos teóricos ni por modelos empíricos. Si bien las posibilidades de un tercero "imparcial" que solucione las contradicciones dejó abierta la posibilidad al Führerprinzip, lo cierto es que las herramientas normativas de excepción continúan vigentes en los sistemas presidencialistas de nuestra Región.

Palabras clave: Democracia; Estado; legalidad; legitimidad; parlamentarismo; Schmitt

\section{Abstract}

In this article we will work on the types of state and their legitimacy in the works of the German jurist Carl Schmitt, avoiding falling into a fragmentary reading or loaded with ideological prejudices. The texts will be reviewed, a selection will be made and the main positions held by the author will be presented, following his own exposition. The anthology will be accompanied by an exegesis of the concept of State, its different types and budgets. As the main result, we will notice the problem of legitimacy in the modern State and its link with the political, which liberalism tried to avoid by equating it with the criterion of legality. Schmitt affirms, on the contrary, that legality and legitimacy could even be contradictory and that is why the types of legislative State, the jurisdictional State and the administrative and governmental State are referenced. Finally, the concept of Law, Law and Democracy is confronted. Schmitt's thesis demonstrates the contradictions that exist between the principle of popular sovereignty and the controls fixed to the parliamentary system. The problems he points out have not been overcome either by current theoretical models or by empirical models. Although the possibilities of an "impartial" third party to solve the contradictions left the possibility open to the Führerprinzip, the truth is that the normative tools of exception are still in force in the presidential systems of our Region.

Keywords: Democracy; legitimacy; legality; parliamentarism; Schmitt; State 


\section{INTRODUCCIÓN}

Sería un mal punto de partida tildar como nacionalsocialista a toda la obra de Carl Schmitt sobre el derecho, la política y la realidad internacional. Su controvertida obra lo llevó a la acusación de proporcionar al nazismo de las armas jurídicas e ideológicas para su acción. Así, se le adjudica, junto con su teoría del decisionismo y su crítica al parlamentarismo de Weimar, el deshonroso privilegio de ser el artífice del Führerprinzip, de justificar teóricamente la doctrina del Lebensraum, de introducir en la política al enemigo como principio definidor; privilegios cuyas culpas no lavó durante los largos años de ostracismo y de olvido que sobrellevó luego de la Segunda Guerra.

Decíamos que es un mal comienzo porque, por un lado, desconoceríamos que Hitler no necesitó más que de la fuerza para justificar sus planes, y por otro lado, porque allí nos detendríamos en lo novedoso de su análisis, sin considerar que durante más de cincuenta largos años, Schmitt se mantuvo en sus posiciones, antes, durante y luego del régimen nacionalsocialista y que, a pesar de ello, siempre desarrolló sus ideas a partir de un hecho histórico concreto ${ }^{1}$.

Su gran preocupación, como jurista que trascendió su ámbito de especialización, fue la necesidad de conservar si no el ordo del Ius publicum europaeum al menos de establecer un nuevo orden frente a las tendencias universalistas que propiciaban la neutralización de la política junto con la culpabilidad del enemigo. Sus conclusiones no se encontraban sustentadas ni dependían de un régimen jurídicopolítico predeterminado, sino que eran justamente los cambiantes acontecimientos históricos, con un común denominador, los que servían de disparadores para proyectar su obra.

Podemos observar, por nuestra parte, que olvidan que sus críticas al parlamentarismo y la teoría del decisionismo, no son tanto posturas en favor del Tercer Reich sino más bien son consecuencia de su

\footnotetext{
${ }^{1}$ Esta posición, junto con su formación católica y su "limitada" teoría del Grossraum lo relegaron, junto a otros iniciales adherentes, a una incómoda posición frente a los extremismos de la doctrina oficial del nacionalsocialismo.
} 
posición crítica frente a la indefinición del liberalismo burgués de la República de Weimar. Por otro lado, que para Schmitt, es el hostis, y no el inimicus, el enemigo que se contrapone al amigo como par y no como criminal.

Pueden encontrarse tres fases en la obra de Schmitt, fases que de ningún modo representan rupturas o saltos en sus pensamientos, sino más bien pausas, tal como lo reconoce Mohler (2007), para retomar los mismos temas desde otra perspectiva. El primer período es el de la República de Weimar, con sus análisis jurídicopolítico de la Constitución y su crítica al Parlamentarismo. Su segundo y más oscuro período es durante el Tercer Reich, cuando debió tomar una posición, elección que ya se encontraba condicionada por sus críticas al liberalismo burgués. De este período son sus tesis a favor de los grandes espacios y su Führerprinzip. El último período es anterior al de la derrota, cuando giró su visión, como especialista en derecho público, al ámbito internacional para advertir los peligros de las posiciones universalistas y la criminalización del enemigo.

Dada la complejidad y vastedad de la obra, en este artículo no se pretende realizar un análisis acabado de toda la problemática que han generado las obras de Schmitt, tanto para sus conciudadanos como para la recepción en Europa y Latinoamérica, sino que se ha optado por efectuar una selección crítica de uno de los temas principales desarrollados durante su primera fase como jurista, el del Estado, con una relación sucinta de los principales puntos de debate.

El problema del Estado, la legitimidad y su ordo construido por el ius publicum europaeum trasunta toda la obra política del pensador alemán aunque prima en sus primeros trabajos: Teoría de la Constitución (1927); Legalidad y Legitimidad (1935) y El concepto de lo "político" (1939). Se retoma también en otras obras posteriores, como El Nomos de la Tierra en el Derecho de Gentes del "Jus publicum europaeum" (1950) o La dictadura escrita (1964), aún cuando no aportan elementos nuevos que modifiquen posturas anteriores. 
Frente a una lectura fragmentaria y cargada de prejuicios ideológicos sobre el conjunto de la obra, preferimos la lectura directa de los textos del propio autor sobre los tipos de Estado y sus legitimidades $^{2}$. Intentaremos realizar en el presente trabajo una relectura de las principales posiciones sustentadas por el autor alemán, para que, siguiendo su propia exposición, podamos alcanzar el sentido profundo de este representante de la autonomía de lo político.

\section{Desarrollo}

\section{El Estado liberal-burgués y lo político}

El origen del fenómeno estatal se vincula en Schmitt con el proceso de secularización, que había implicado: en primer lugar, la centralización y clarificación de las competencias; en segundo lugar, la finalización de las guerras religiosas; y por último, al constituirse como unidad política con firmes fronteras hacia el exterior, la posibilidad de entablar relaciones directas con otras estructuras territoriales estatales.

La particularidad histórica única, totalmente incomparable, de aquello que puede llamarse «Estado» en un sentido específico reside en el hecho de que este Estado es el vehículo de secularización. Por ello, la formación de conceptos del Derecho de Gentes no conoce en aquella época más que un solo eje: el Estado territorial soberano (Schmitt, 2005, p. 117).

Para Schmitt, el Estado de su época, que también es la nuestra, es el Estado del derecho liberal-burgués y debía entenderse como la forma moderna, y por lo tanto histórica, de la unidad política que recibía su significación histórica de raíces espirituales como contraposición y adversario de la Monarquía absoluta.

\footnotetext{
${ }^{2}$ Dejamos de lado algunas críticas coyunturales, como las dirigidas al modelo de la Constitución de Weimar, para trabajar los aspectos aún vigentes de su crítica.
} 
El Estado moderno ha nacido históricamente de una técnica política. Con él comienza, como un reflejo teorético suyo, la teoría de la razón del Estado, es decir, una máxima sociológica-política que se levanta por encima de la oposición de derecho y agravio, derivada tan solo de las necesidades de afirmación y la ampliación del poder político (Schmitt, 1968, p. 44).

Schmitt ve al Estado moderno como heredero de la Monarquía absoluta en cuanto había sido ésta la que había creado la forma política del Estado nacional y en especial a la Nación como elemento coagulante.

En esto se basa, al menos para el liberalismo del Estado de derecho continental de los siglos XVIII y XIX, el valor jurídico de la monarquía absoluta, que aniquiló los poderes feudales y estamentales, creando así una soberanía en el sentido moderno de unidad estatal. La unidad así lograda es el presupuesto fundamental de la literatura revolucionaria del siglo XVII. El esfuerzo por aislar a los individuos y eliminar a todo grupo social en el seno de1 Estado, a fin de enfrentar entre sí de una manera inmediata al individuo y el Estado, se pone de relieve en la exposición de las teorías del despotismo legal y del contrato social (Schmitt, 1968, pp. 261-262).

Sólo entonces podía entenderse que en sus orígenes el Estado liberal-burgués haya tomado atributos externos propios de la Monarquía, tales como su Majestad y los principios de la representación unitaria y soberana propios del Estado Absoluto. Para Schmitt, los momentos de crisis es cuando se exterioriza que por debajo del Estado de Derecho subyace la Monarquía.

Cuando la Nación como sujeto del poder constituyente se enfrenta con el Monarca absoluto y suprime su absolutismo, se coloca en su puesto de la misma absoluta manera. [...] El vigor político de este acontecimiento condujo a un aumento del poder del Estado, a la más intensa unidad e indivisibilidad, unité e indivisibilité (Schmitt, 1982, p. 71).

Si bien en los momentos decisivos para la construcción de este Estado liberal-burgués, la lucha de la burguesía aparecía como lucha por el sistema parlamentario, no debía olvidarse al Parlamento, el 
cual en sus orígenes, representaba una forma aristocrática, en cuanto la idea del diputado estaba vinculada a un hombre seleccionado que por su inteligencia y preparación debía cuidar del todo político en cuanto tal.

El dominio del Parlamento es un caso de Aristocracia (o, en la forma de subespecie: Oligarquía). La Aristocracia es, en cierto sentido, una forma mixta de gobierno. En la doctrina de la forma mixta de gobierno aparece siempre como una forma especialmente recomendable, porque ocupa el punto medio entre Monarquía y Democracia, y por eso envuelve ya una mezcla (Schmitt, 1982, p. 216).

Es que para Schmitt la democracia parlamentaria instaurada por la burguesía, basada en la instrucción y la propiedad, no había aún adoptado una decisión, en su sentido estricto, pues existían ciertos contrastes que debían permanecer latentes para satisfacer las pretensiones tanto liberales como democráticas, y entre estas decisiones, la opción por la representación o la identidad ${ }^{3}$.

No puede decirse que la burguesía, cuando luchaba en Europa por su Estado de derecho, prefiriera definitivamente uno de los dos principios políticos-formales, identidad o representación. Luchaba contra toda especie de absolutismo estatal, tanto contra una Democracia absoluta como contra una Monarquía absoluta; contra la identidad extrema como contra la extrema representación. En la medida en que propugnaba ciertas instituciones políticas más allá de las simples exigencias moderadoras y temperadoras propias del Estado de Derecho, su finalidad era el «sistema parlamentario». Este sistema es la exigencia política propia de la burguesía liberal. Se basa, como después, al discutir los distintos principios formales, se verá más al detalle, en una peculiar vinculación, contrapeso y relativización de elementos formales y estructurales, monárquicos, aristocráticos y democráticos (Schmitt, 1982, p. 215).

Schmitt desvela estas tensiones al punto de identificar a la indefinición del gobierno con las aspiraciones de burguesía liberal:

${ }^{3}$ En esta indefinición Schmitt apunta sus dardos más venosos a la Constitución de Weimar. 
La burguesía hacía valer los derechos de la institución parlamentaria y la representación popular para contrarrestar las pretensiones políticas de una monarquía fuerte; para salvar la libertad y la propiedad privada ante un modelo de democracia proletaria buscaba la protección en un gobierno monárquico fuerte; la burguesía apelaba a los principios de libertad e igualdad contra la monarquía y la aristocracia; finalmente, para salvar la propiedad privada y a un concepto de ley propio del Estado de Derecho, la misma burguesía aplicaba esos principios con un carácter sagrado para limitar cualquier democracia de masas, pequeño-burguesa o proletaria (Schmitt, 1982, p. 298).

Schmitt señala que para el proceso de constitucionalización moderna se había impuesto un determinado tipo de Constitución ideal, con ciertos derechos y garantías propios de la libertad burguesa. Pero estos derechos y garantías habían asignado un específico contenido a la organización del Estado que desplaza lo político a una esfera de competencias limitadas y circunscriptas. Expresamente señala que "el ideal pleno del Estado burgués de Derecho culmina en una conformación judicial general de toda la vida del Estado" cuando en verdad "su esencia estriba en que adopta la decisión política" (Schmitt, 1982, p. 144).

La pretensión de limitar el poder en un principio básico de mensurabilidad de todas las manifestaciones de poder del Estado, no tenía en cuenta que la Revolución Francesa, con su sistema de división de poderes, no había logrado limitar el poder, sino que por el contrario, había aumentado el poder del Estado. Y es que, al no constituir la Constitución moderna un pacto entre Príncipe y estamentos, sino como decisión política de un pueblo homogéneo, uno e indivisible, no podía haber límite alguno para esa unidad política soberana.

En la transición del absolutismo regio al Estado de derecho burgués se presupuso, como evidente por sí mismo, que en lo sucesivo estaba asegurada de una manera definitiva la unidad solidaria del Estado. La seguridad podía ser alterada por tumultos y motines, pero 1a homogeneidad no estaba amenazada seriamente por los agrupamientos sociales dentro del Estado. 
Si un individuo o un tropel de individuos alteran el orden jurídico, esta es una acción cuya reacción puede ser calculada y regulada previamente, del mismo modo que la ejecución procesal civil y penal delimita con exactitud la esfera de sus medios de poder, en lo cual radica la regulación jurídica de su procedimiento (Schmitt, 1968, p. 261).

Para Schmitt, la Constitución es válida cuando emana de un poder, fuerza o autoridad constituyente que se establece por su voluntad, esto es, una magnitud del Ser como origen de un Deber-Ser cuya esencia es también justicia y no sólo positividad.

Poder constituyente es la voluntad política cuya fuerza o autoridad es capaz de adoptar la concreta decisión de conjunto sobre el modo y forma de la propia existencia de la unidad política, determinando así la existencia de la unidad política como un todo. De las decisiones de esta voluntad se deriva la validez de toda ulterior regulación legalconstitucional. Las decisiones, como mías, son cualitativamente distintas de las normaciones legal-constitucionales establecidas sobre su base (Schmitt, 1982, pp. 93-94).

Al ser siempre la lucha por la representación, una lucha por el poder político, para Schmitt, hace al Estado una unidad de decisión, que depende de su carácter político.

[...] el Estado se basa como unidad política en una vinculación de dos contrapuestos principios de formación, el principio de la identidad (del pueblo presente consigo mismo como unidad política, cuando, por virtud de propia conciencia política y voluntad nacional, tiene aptitud para distinguir entre amigo y enemigo), y el principio de la representación, en virtud del cual la unidad política es representada por el Gobierno (Schmitt, 1982, p. 213).

De todas formas, el fenómeno de lo político no se explica a partir del Estado porque existen procesos políticos que no pueden reducirse a la dimensión estatal.

En general, «lo político» es asimilado, de una manera u otra a lo «estatal» o, como mínimo, se refiere al Estado. Entonces el Estado aparece como algo político, y lo político como algo estatal: se trata claramente de un círculo vicioso (Schmitt, 1984, p. 16). 
La categoría de lo político, si es confundida con lo estatal, conduce al fenómeno del Estado Total propio de la identidad de la sociedad con el Estado. El peligro estribaba en que la identificación entre el Estado y sociedad debilitaba la politicidad natural del Estado en el sentido de que si todo es político ya nada lo es. El Estado, como proceso histórico, había evolucionado desde su aparición en el Renacimiento, al Estado Absoluto del siglo XVII y de allí, por influencia del liberalismo, a constituirse en una instancia de neutralización durante el siglo XIX.

Dado que la técnica no era una actividad neutral sino un instrumento de dominio utilizado por el Estado, prevé su evolución hacia el «Estado total».

La totalidad de la esfera estatal estaba relacionada con la tendencia del Estado a intervenir en todos los ámbitos, no solamente políticos sino también económicos y sociales, bajo la forma de un Estado asistencial de partidos.

Un Estado pluralista de partidos se transforma en un Estado total no por su fortaleza y su eficiencia, sino por su debilidad: interviene en los dominios de la vida porque se espera que pueda satisfacer los requerimientos de todos los intereses (Schmitt, 1971, p. 150).

Esta es la idea del Estado total por su omnipresencia en todos los ámbitos a causa de su falta de decisión de las cuestiones esenciales ${ }^{3}$. Para Schmitt, la política liberal intentaba neutralizar y despolitizar al fenómeno político y sin embrago, no podía sustraerse de él, por cuanto, al instaurar una dinámica de competencia y discusión eterna, el Estado se unifica con la sociedad y de esa identidad deviene la idea de un imperialismo de tipo económico que aplica medios de coerción económicos, que no por ello dejan de ser políticos.

\footnotetext{
${ }^{3}$ La idea del Estado total no se confunde en Schmitt con la del Estado totalitario porque dada su configuración histórica estaba destinado a desaparecer como las anteriores.
} 
Como consecuencia de esa política liberal, los conflictos otrora sociales y económicos se transformaban en conflictos políticos frente a los cuales el Estado no puede dejar de intervenir, interesándose así, en todos los sectores de la realidad. Para Schmitt, "ahora como antes, el destino continúa siendo representado por la política, pero mientras tanto solamente ocurre que la economía se transforma en algo «político» y por lo tanto, también en «destino»" (Schmitt, 1984, p. 75).

El problema de la legitimidad en el Estado moderno y los tipos de Estado

En el profundo estudio Legalidad y Legitimidad de 1935, Schmitt (1971) analiza la crisis de la República de Weimar que explica como es consecuencia de la política liberal del siglo XIX. La República de Weimar había pretendido realizar el ideal burgués-liberal del Estado sin política, lo cual conducía a la no-decisión, esto es, a la parálisis y a la impotencia. Pero el fundamento último del estudio sobre legalidad y legitimidad consiste en el análisis de los arcana reipublicae, es decir, de los principios de legitimidad, que como fuerzas propulsoras que actúan en el interior del Estado, hacen posibles la coexistencia pacífica.

Schmitt sostiene que la legalidad y la legitimidad no son conceptos equivalentes como lo afirmaba la teoría liberal. Por el contrario, podían llegar a ser opuestos y contradictorios. Schmitt señala como para la Iglesia romana no había distinción posible por cuanto, si la directiva es divina, la jerarquía legal es siempre legítima. Pero con el desarrollo constitucional del Estado continental europeo, la separación se había convertido en un destino, que para Schmitt, parece ser trágico.

La alternativa entre legalidad y legitimidad había sido sólo una consecuencia de la Revolución Francesa y de la pretendida restauración monárquica de 1815, divergencia que se enfrentó drásticamente contra la legalidad instaurada por Napoleón, aún por entonces vigente. 
Para el progreso revolucionario, la legalidad, representaba la máxima expresión de racionalidad y una forma históricamente más elevada que la legitimidad. Pero el más brusco contraste se produce, según Schmitt, con el Manifiesto Comunista, ya que desde entonces la Ley del Estado clasista burgués es vista como enemiga del proletariado.

La visión positivista no comprendía, según Schmitt, como la legalidad no era en su origen otra cosa más que un producto del racionalismo occidental y tan sólo una forma de legitimidad, la cual al estar opuesta a la legitimidad dinástica, hacía recaer la justificación del Estado en la decisión soberana del Pueblo.

El positivismo jurídico, a la sazón predominante, estaba basado en la creencia en el poder casi omnímodo del legislador y en la plausible consecuencia de que, si bien el legislador ha de tener un gran poder, las facultades de aquel que puede introducir reformas en la Constitución han de ser forzosamente mucho mayores (Schmitt, 1971, p. $\mathrm{XI})$.

Producto de esta confusión Schmitt describe cuatro tipos de Estados: el legislativo, el jurisdiccional, el gubernativo y el administrativo; a los que le corresponden cuatro tipos de legitimación propios, la legitimación legal, la jurisdiccional, la gubernativa y la administrativa.

a) El Estado legislativo

Ubica la política liberal dentro del Estado legislativo, al cual distingue del Estado jurisdiccional y el administrativo. El Estado de Derecho se basa en el «imperio de la Ley» y por ello es Estado legislativo.

Por «Estado legislativo» se entiende aquí un determinado tipo de comunidad política, cuya peculiaridad consiste en que ve la expresión suprema y decisiva de la voluntad común en la proclamación de una especie, cualificada de normas que pretenden ser Derecho, y a las que, en consecuencia, son reducibles todas las demás funciones, competencias y esferas de actividad del dominio público (Schmitt, 1971, p. 4). 
Para Schmitt, el Estado legislativo estaba dominado por normas impersonales, por la ley en su calidad de acto, es decir, por normas generales y predeterminadas, separadas del momento de aplicación al caso concreto.

Se buscaba así la crear normas mensurables y determinables en su contenido siendo el poder judicial un mero organismo de aplicación, esto es, sin capacidad de interpretación. Así, bajo este Estado, al imperar las leyes, y no los hombres, las autoridades o un poder soberano, son las leyes, en cuanto acto de razón iluminado e ingenioso, las que gobiernan.

El sentido último y propio del principio fundamental de «legalidad» de toda la vida Estatal radica en que, en definitiva, ya no se domina ni se manda, porque las normas vigentes solo se hacen valer de una manera impersonal. La justificación de este Estado está en la legalidad general de todo el ejercicio del poder estatal. El fundamento del deber de obediencia y la justificación de la supresión de todo derecho de resistencia están constituidos por un sistema de legalidad cerrado. La forma específica en que se manifiesta aquí el Derecho es la ley, y la justificación específica del poder coercitivo del Estado es la legalidad (Schmitt, 1971, p. 5).

El Estado legislativo había desarrollado su sistema de justificación a partir de la noción de legalidad, rechazando no sólo la legitimidad sino también la autoridad soberana basada en sí misma. "La legitimidad y la legalidad se reducen ambas aquí a un concepto común de legitimidad, mientras que la legalidad es justamente lo contrario de la legitimidad" (Schmitt, 1971, p. 14).

El modelo de Estado Legislativo busca reducir la política a funciones secundarias y por ello legalidad y legitimidad aparentemente coincidirían. Pero para esto, era necesario que la autoridad recayese en la libre discusión de los legisladores para que lograsen, con la razón, alcanzar un sistema general de normas de modo que los gobernantes simplemente las apliquen. Sin embargo, la existencia de ciertos contenidos axiológicos materialmente protegidos por una mayoría especial estaban en contradicción con la neutralidad axiológica del Estado legislativo parlamentario. Desde una posición teórica, 
Schmitt sostiene que el derecho como acto legislativo no puede valer como sistema de normas universales por cuanto no se puede legislar sobre todo. En contra del positivismo jurídico, afirma que el derecho no se reduce a un sistema de suma de leyes sino que su esencia se encuentra en la voluntad política que la genera, esto es, en la decisión. Así, el fenómeno de lo político tiene primacía sobre el derecho.

\section{b) El Estado jurisdiccional}

Por su parte, en el Estado jurisdiccional la voluntad política decisoria es pronunciada en último término por el juez al dirimir el litigio y no por el legislador que crea normas.

Expresión típica del Estado jurisdiccional es la decisión de casos concretos, en la que el Derecho justo, la justicia y la razón se manifiestan de manera inmediata, sin la mediatización de normas generales previamente elaboradas y sin caer, por tanto, en el normativismo de la mera legalidad (Schmitt, 1971, p. 6).

Es el Estado jurisdiccional el que parece que estar más cerca del Estado de Derecho, aunque sea el propio juez el que lo pronuncie.

\section{c) El Estado administrativo y el Estado gubernativo}

Por último y como contraposición al Estado legislativo, Schmitt presenta al Estado gubernativo, que puede presentar una variante no autoritaria: el Estado administrativo.

[...] está el Estado gubernativo, que encuentra su expresión característica en la voluntad personal soberana y el mando autoritario de un jefe de Estado que ejerce personalmente el gobierno. Pero es todavía concebible otro tipo de Estado, en el que el mando y la voluntad no sean autoritarios ni personales y, a pesar de todo, no sean meras aplicaciones de normas soberanas, sino tan solo ordenanzas de carácter objetivo: el Estado administrativo, en el que ni el gobierno de los hombres ni el imperio de las normas es soberano, sino en el cual, y según la célebre fórmula, «las cosas se administran por sí mismas» (Schmitt, 1971, p. 7). 
Para Schmitt, el Estado se encontraba en un proceso de transformación y viraje hacia el Estado total, con su tendencia hacia la planificación, transformación que asume la forma del Estado gubernativo o administrativo.

Los Estados gubernativo y administrativo son los más adecuados como instrumentos para llevar a cabo grandes transformaciones radicales, de signo revolucionario o reaccionario, y para configuraciones de gran envergadura, planificadas y calculadas con amplias miras. El Estado legislativo es el vehículo típico de una era reformista-revisionista-evolucionista, equiparada con programas de partido, que trata de realizar el «progreso» mediante leyes justas, de un modo legal parlamentarios (Schmitt, 1971, pp. 11-12).

\section{El Derecho, la ley y la democracia}

Schmitt sostiene la naturalidad que en el Estado liberal, con el triunfo de las ideas de la representación popular, el Derecho apareciese expresado esencialmente en forma de ley. Las nociones de la ciencia del Derecho estaban dominadas por una serie de identidades y congruencias entre el Derecho y la ley. Así, el Derecho se identificaba con la ley y ésta con la regulación estatal realizada con la cooperación de la representación popular.

En esta congruencia entre el Derecho y la ley descansaban, en definitiva, todos los sistemas e inventarios de conceptos, fórmulas y postulados jurídico-políticos que se desarrollaron en el curso del siglo XIX y que aún conservan efectividad. El Estado es la ley, la ley es el Estado. Sólo a la ley se debe obediencia; sólo frente a ella desaparece el derecho de resistencia. Sólo hay legalidad, no autoridad ni mando que proceda de arriba (Schmitt, 1971, p. 28).

Dentro de este sistema, la fuente del Derecho es siempre una: el legislador que tiene que mantener el monopolio de la legalidad. En un Estado legislativo el concepto de ley debe ser claro, discernible y reconocible con una armonía material y llena de sentido. Es por esto, que para Schmitt, en el Estado de Derecho la vinculación del Legislador a la Ley es posible sólo en tanto que la Ley es una norma 
con ciertas propiedades, entre ellas, la rectitud, la justicia, y la razonabilidad. En este sentido, el concepto de ley para servir de soporte del Estado legislativo parlamentario debe poseer ciertas cualidades, entre ellas, no ser neutral frente a sí mismo y frente a sus presupuestos, pues si se convierta a la ley en mera resolución parlamentaria, se terminan todas las garantías de justicia y racionalidad para convertirse la ley en una noción aritmética de cálculo de mayorías.

Todo lo que se diga del imperio de la Ley o del imperio de la norma, todas las expresiones relacionadas con la «normatividad», son, en sí mismas, contradictorias y confusas cuando desaparece ese carácter general y puede pasar por «norma» o «Ley» cualquier mandato, cualquier medida (Schmitt, 1982, p. 152).

La Ley concebida como medio de protección de la sociedad, formalmente representada, contra la intromisión a la esfera de la libertad y propiedad por parte del Rey, no planteó dificultades teóricas mientras se mantuvo la estructura dualista entre sociedad y Estado. La única problemática subyacente era la dependencia del Rey respecto de la Ley, tal como lo señala en su obra La dictadura (Schmith, 1968):

La cuestión es esta: ¿debe el rey depender de la ley o la ley del rey?, rex a lege an lex a rege pendebit?. De aquí resulta una división simple de los poderes: legislación y ejecutivo, donde la ley es la voluntad del pueblo, es decir, de la representación estamental del pueblo, y el príncipe rige como execurar, gubernator, curator, minister legis y primer servidor del Estado (supremus Regni officiarius), como organum de la ley, pero solo como cuerpo, no como alma de la ley (Schmitt, 1968, p. 51).

Pero, a partir de la lógica democrática y la disolución de ese dualismo, pareció natural calificar como «Ley», con su majestad y dignidad, a toda manifestación de la voluntad popular de mayoría presente.

Porque, según el presupuesto democrático, el pueblo homogéneo reúne todas las propiedades que garantizan la justicia y la racionalidad de la voluntad por él expresada. No existe ninguna democracia sin el presupuesto de la bondad del pueblo y de que, por lo tanto, su voluntad constituye un móvil suficiente (Schmitt, 1971, p. 37). 
Es que bien pronto se había perdido el sentido específicamente político de la democracia y del citoyen virtuoso de Rousseau por una dimensión representativa meramente cuantitativa y aritmética, propia del individualismo liberal.

Para Schmitt, como consecuencia de desligar el concepto formal del político de la Ley, ella se convertía en un concepto meramente formal carente de un contenido relacionado con la razón y la justicia.

El concepto democrático del Ley es un concepto político, no un concepto de ley propio del Estado de Derecho; arranca como potestas del pueblo y proclama que la ley es lo que el pueblo quiere [...]. El concepto de ley propio del Estado de Derecho, que transforma la democracia en una Democracia constitucional, es el que hace posibles aquí garantías contra injusticias y desigualdades (Schmitt, 1982, p. 252).

Es así que señala que toda ordenanza, mandato, disposición, orden o instrucción puede hacerse legal y jurídica mediante una resolución del parlamento o de una instancia que participe en el proceso legislativo o bien cuando la invasión a la libertad y la propiedad tiene lugar con arreglo a una Ley.

Lo «puramente formal» se reduce entonces a la palabra vacía y a la etiqueta de «ley», perdiendo su conexión con el Estado de Derecho. [...] Entonces ya no necesita la ley, ni siquiera en la intención, ser una regulación duradera general (que otorga trato igual a los iguales), con un contenido mensurable y determinado; siempre que observe el procedimiento legislativo, el legislado puede hacer lo que quiera; esto siempre es «ley» y siempre crea «Derecho» (Schmitt, 1971, p. 32).

Así, se concibe un nuevo concepto formal de ley ligado ahora a la confianza en la armonía entre la mayoría parlamentaria y la voluntad homogénea del pueblo. Por ello se concibe al Parlamento, en la democracia parlamentaria, como expresión de la voluntad inmediata del pueblo soberano, esto es, como resolución momentánea de la mayoría parlamentaria del momento. 
Pero en este lugar se debe subrayar otro requisito, de cuya imprevisibilidad no se tiene, las más de las veces, suficiente conciencia: La Constitución escrita del Estado legislativo parlamentario tiene que limitarse fundamentalmente a regulaciones orgánicas y de procedimiento. Este requisito responde tanto a la neutralidad liberal relativa como a la neutralidad funcionalista absoluta de un sistema cuyo procedimiento y cuyos métodos requieren estar abiertos y accesibles a diversas opiniones, direcciones, movimientos y objetivos (Schmitt, 1971, p. 39).

Esta falta de contenido quita a la legalidad toda fuerza de convicción por cuanto la supuesta neutralidad política es en verdad neutralidad frente a lo justo o injusto y negación de todo derecho de resistencia.

En una situación de neutralidad en cuanto al contenido, o con un concepto funcionalista de la legalidad falto de todo contenido, no puede ya existir la primera clase de tirano, es decir, la del que hace un uso ilegal del poder legalmente obtenido; pero la mayoría tampoco podría ser nunca "tirano sin título jurídico", toda vez que la mayoría se ha convertido en el único título jurídico para la posesión legal del poder. Solo es ilegal y «tirano» quien ejerza el poder estatal o para estatal sin tener e su parte la mayoría el 51 por 100. Por el contrario, quien tenga esta mayoría ya no cometerá injusticias, pues todo lo que haga se convierte en Derecho y en legalidad (Schmitt, 1971, p. 45).

\section{Legitimidad parlamentaria y legitimidad plebiscitaria}

Para Schmitt, el sistema Parlamentario instauraba un sistema de "premio de supralegalidad" basado en la apropiación del poder legal en favor de la mayoría. Éste consistía la posibilidad de que la mayoría que controlase el 51\% del Parlamento, abusando de su poder legalmente adquirido, modificase las reglas de juego contra el $49 \%$ de la minoría.

El 51 por 100 de los votos en las elecciones da por resultado la mayoría parlamentaria; el 51 por 100 de los votos del Parlamento produce el Derecho y la legalidad; la confianza en el gobierno del 51 por 100 del Parlamento produce el gobierno parlamentario legal (Schmitt, 1971, p. 39). 
Este sistema, para Schmitt, es admisible cuando se presupone la homogeneidad sustancial de un pueblo integral, unitario e indivisible, pero la existencia de una minoría pone al descubierto la falacia de la identificación entre gobernantes y gobernados y revela, por el contrario, la existencia de un despotismo de una mayoría.

La identidad democrática descansa en la idea de que todo lo que hay dentro del Estado como actuación del Poder estatal y como Gobierno permanece dentro de la homogeneidad sustancial (Schmitt, 1982, p. 233).

Si se suprime el presupuesto de la homogeneidad nacional indivisible, entonces el funcionalismo sin objeto ni contenido, resultante de la verificación puramente aritmética de la mayoría, excluirá toda neutralidad y toda objetividad; será tan sólo el despotismo de una mayoría cuantitativamente mayor o menor sobre la minoría vencida en el escrutinio y, por lo tanto subyugada (Schmitt, 1971, p. 43).

Para Schmitt existe, sin embargo, un principio de justicia y de autoconservación que impide que este sistema de legalidad se desmorone: la igualdad de "chance" para alcanzar esa mayoría. De otra manera, el que obtuviese la primera mayoría podría instaurarse legalmente como poder permanente, transformando la autoridad del Parlamento, en una mera cuestión de cantidades, en una pulseada entre una mayoría y una minoría.

Quien domine el 51 por 100 podría ilegalizar, de modo legal, al 49 por 100 restante. Podría cerrar tras sí, de modo legal, la puerta de la legalidad por la que ha entrado y tratar como a un delincuente común al partido político contrario.... (Schmitt, 1971, p. 39).

Esta posibilidad, no se le aparecía como extraña o desviada a este sistema. Al ser una consecuencia del monopolio de la legalidad parlamentaria, el partido dominante adquiere la posesión legal de los medios del poder estatal y político, como una plusvalía política adicional, mayor al simple poder de establecer las normas. 
El partido dominante dispone de toda la preponderancia que lleva consigo, en un Estado donde impera esta clase de legalidad, la mera posesión de los medios legales del poder. La mayoría deja repentinamente de ser un partido; es el Estado mismo (Schmitt, 1971, p. 49).

Por ello, el renunciar a la igualdad de "chance» significa para el Estado legislativo parlamentario renunciar a sí mismo, a su justicia y a su legalidad. Y sin embargo, para Schmitt, en todo momento crítico la igualdad de "chance" queda anulada por tres hechos: en primer lugar, por la mera presunción de legalidad, presunción a la que ningún poder puede renunciar; en segundo lugar, por la ejecutividad inmediata que hace que toda decisión de la justicia llegue demasiado tarde; y en tercer lugar, por el hecho de ser el propio partido el dominante puede determinar, por sí sólo, cuándo comienza la ilegalidad del competidor ${ }^{4}$.

Señala además, dado que ninguna norma se aplica o interpreta por sí misma, surge en este marco la necesidad de ciertas instituciones orgánicas y concretas para proteger esa jerarquía normativa contra el legislador ordinario. Ese tercero imparcial, guardián de la Constitución, se convertiría entonces en un tercero superior, supraparlamentario y suprademocrático. Pero, sin ese tercero imparcial, los órganos jurisdiccionales ordinarios, podrían desvirtuar el contenido de esa norma superior o hacer pasar por normas ordinarias las causas sometidas a la ley superior.

En el segundo caso, al introducirse un plus cuantitativo, se crearía un tercer legislador ratione materiae, quebrando con ello las bases del Estado legislativo parlamentario y su concepto de legalidad. En este último sentido, Schmitt afirma que exigir el 66,66\% implica introducir una diferencia no sólo cuantitativa si no, antes bien,

\footnotetext{
${ }^{4}$ Ante esta realidad, cada partido, en la previsión de que el otro cierre tras de sí la igualdad de chance luego de lograr la mayoría, acusa al otro su ilegalidad y se hace pasar por guardián de la legalidad llevando con ello a una situación que califica como «alegal» y «aconstitucional».
} 
cualitativa por cuanto expresa una desconfianza antidemocrática en la mayoría simple ya que para Schmitt, el escrutinio democrático no presupone declarar una voluntad opresora de una mayoría sino descubrir la unidad profunda del pueblo.

Las dificultades que se ponen a la formación de la mayoría, puramente cuantitativas, sólo se manifiestan negativamente en la práctica, como un freno; no contienen ningún principio general positivo de justicia o de razón, ni un punto de vista específicamente constitucional, ni son por esencia algo democrático. Sería, en suma, una clase especial de «justicia» el declarar que una mayoría es tanto mejor y más justa cuanto más aplastante sea, y afirmar en abstracto que el que noventa y ocho hombres maltraten a dos hombres no es, ni con mucho, tan injusto como el que cincuenta y un hombres maltraten a cuarenta y nueve. La matemática pura se convierte aquí en inhumanidad pura. Pero tampoco sería en modo alguno especialmente democrático decir que la calidad y la justicia de una ley dependen de la magnitud cuantitativa de la mayoría con que fuera aprobada y que, por tanto, sin necesidad de atender al contenido, una resolución adoptada por el 67 por 100 de los votos es una norma superior en 16 grados a una resolución que solo ha obtenido el 51 por 100. La distinción entre leyes ordinarias y leyes de rango superior descansa, en los casos que aquí interesan, no en el principio del quorum, sino en la voluntad de la Constitución; pero, según los principios democráticos generales, la misma Constitución puede aprobarse por mayoría simple (Schmitt, 1971, pp. 62-63).

Con este adicional aritmético se destruye el presupuesto democrático de la mayoría simple de la suma de lo homogéneo y la momentaneidad representada en el Parlamento a partir de la homogeneidad del pueblo por un nuevo presupuesto que afirma su división en un conjunto de complejos heterogéneamente organizados.

Esta mayoría calificada, por otra parte, podría aún por encima de sí misma y de su momentaneidad crear efectos y vínculos duraderos que restrinjan la voluntad del pueblo, de manera legal aunque no democrática. Surge entonces que la solución a los peligros de la mayoría simple puede conducir a riesgos aún mayores. 
$\mathrm{Al}$ parecer, como consecuencia del requisito de una mayoría más difícil de lograr, aparece ahora una nueva clase de momentaneidad e instantaneidad: la ley superior (ley constitucional) es entonces simplemente la voluntad momentánea de la mayoría momentánea de dos tercios. Pero esta clase nueva y "superior» de momentaneidad está en contradicción con la clase primera e «inferior», porque no está concebida como desprovista de contenido y neutral en cuanto a los valores y, por tanto, tampoco de una manera funcionalista (Schmitt, 1971, p. 71).

Pierde con ello el Parlamento su papel de centro normativizador por la aparición de un nuevo legislador, el legislador extraordinario superior, al cual Schmitt vinculará con la aparición de una nueva legitimidad contraria a la legalidad del Estado legislativo. Esa nueva legitimidad es la legitimidad plebiscitaria.

Si el Pueblo es en la Democracia sujeto titular del poder constituyente, se derivaban ciertas consecuencias necesarias: siendo una instancia no firme ni organizada y debiendo ser capaz de decisiones y actuaciones políticas, la forma natural de manifestación de su voluntad inmediata no puede ser otra que la aclamación.

En los grandes Estados modernos, la aclamación, que es una manifestación natural y necesaria de vida de todo pueblo, ha cambiado su forma. Se manifiesta como "opinión pública». Pero siempre puede el pueblo decir sí o no, asentir o rechazar; y su sí o no será tanto más sencillo y elemental cuanto más se trate de una decisión fundamental sobre la propia existencia común (Schmitt, 1982, p. 100).

Para la doctrina democrática, siendo el Pueblo anterior a cualquier procedimiento constitucional y estando por ello sobre cualquier formalidad y normación, la Democracia había previsto encauzar esas manifestaciones a través de ciertos canales, sean éstos, el referéndum, el asentimiento o el plebiscito.

Pero Schmitt reconoce con la introducción en la Constitución de Weimar del procedimiento legislativo popular, propio de la democracia directa, se daba una nueva relativización al procedimiento legislativo ordinario por la coexistencia de estos dos sistemas de legitimidad representativas de dos Estados y lógicas distintas. 
[...] aquí aparece el pueblo como legislador extraordinario frente al Parlamento, y su carácter extraordinario y supraordenado constituye una ratione supremitatis derivada de su calidad de soberano (Schmitt, 1971, p. 95).

Si el Parlamento representa la voluntad del Pueblo, como titular formal de la soberanía, éste puede por sí rever cualquier decisión tomada por aquél o decidir cualquier cuestión perdiendo entonces validez la representación del Parlamento frente a un procedimiento plebiscitario más fuerte. El Parlamento, con esta nueva legitimidad, queda relegado a una institución paralela a la expresión de voluntad directa del pueblo, lo cual hace que la decisión plebiscitaria también adquiera fuerza de ley. Así, estos dos sistemas representan la lucha entre dos clases de Derecho.

[...] estos elementos plebiscitarios modifican la calidad del Parlamento mismo, transformándolo en una mera interpolación del sistema plebiscitario, pero no modifican inmediatamente el procedimiento legislativo previsto en la Constitución ni el sistema de legalidad basado en dicho procedimiento. Más bien puede sostenerse que la decisión plebiscitaria es también una «resolución con fuerza de ley» en el sentido del sistema de legalidad. Entonces la decisión plebiscitaria tiene el mismo valor que la ley del Parlamento; no está colocada por encima de ella, sino a su lado (Schmitt, 1971, pp. 98-99).

\section{Resultados}

\section{El conflicto de legitimidades}

En el Estado actual resurge el conflicto de legitimidades, no ya entre la legitimidad monárquica y la democrática sino entre las legitimidades propias de las distintas estructuras estatales: el Estado parlamentario, el Estado jurisdiccional y el Estado burocráticoadministrativo. Esta deslegitimación de la legalidad cerrada del Estado Parlamentario por una pluridad de legitimidades, no podía 
tener otra consecuencia que la paralización del Estado y su reconfiguración como una simple institución social que se ocupa de todo lo no esencial a causa de su impotencia.

La necesidad de las mayorías calificadas conlleva, en un Estado pluralista de partidos, a plantear la exigencia de una ley de compromiso entre varios complejos heterogéneos de partidos que actúan ora como estado, ya como entidad social, o como mero partido influyendo sobre la voluntad estatal sin incurrir en las responsabilidades del mando. Esta actitud convertía al Parlamento en escenario de polémica y lucha por la posesión de primas y plusvalías políticas.

Los partidos tratan de sacar provecho de la legalidad de la posesión momentánea el poder y, sobre todo, de las primas y plusvalías políticas; pero en la misma medida en que entierran al sistema de legalidad del Estado legislativo parlamentario, chocan con el legalismo de un sistema opuesto a dicho Estado, es decir, chocan con el sistema de legitimidad plebiscitario democrático (Schmitt, 1971, p. 143).

Desde el momento en que las mayorías parlamentarias buscan no ya ejercer su actividad en el marco de un sistema normativo de bienestar general sino que actúan como facciones de partidos que tratan o apoyar o derribar al gobierno, el debate se tornó en polémica y negociación y la ley perdió su prestigio y solemnidad para transformarse en voluntad momentánea de las mayorías circunstanciales.

El Parlamento, en la mayor parte de los Estados, no es ya hoy un lugar de controversia racional donde existe la posibilidad de que una parte de los diputados convenza a la otra y el acuerdo de la Asamblea pública en pleno sea el resultado del debate. Antes bien, las organizaciones sólidas de partido forman una representación siempre presente de ciertos sectores de las masas electorales. La posición del diputado se encuentra fijada por el partido; la coacción del grupo es una práctica del parlamentarismo actual, sin que tengan significación diversas apariencias (Schmitt, 1982, p. 306). 
Por otra parte, la sanción de numerosas disposiciones particulares no legislativas, pero que por tener carácter obligatorio, contaban con fuerza de ley, trivializaban las verdaderas normas legislativas de carácter general y destruían el principio liberal de la igualdad ante la ley.

Consecuentemente, la ley se convertía en una disposición, con "probabilidad de obediencia forzosa", dirigida a las autoridades estatales encargadas de aplicar las leyes. Ya no era posible distinguir entre «ley» y «medida». Toda orden pública o secreta podía ser denominada ley porque era dictada por autoridades estatales; su probabilidad de obediencia forzosa no era menor, sino quizá aún mayor que la de estipulaciones aclamadas y proclamadas en público tras las discusiones más complicadas (Schmitt, 2005, p. 58-59).

La consecuencia de todo esto no podía ser otra que la constitución de un Estado débil, que desmembrado en un Estado pluralista de partidos, tiende a buscar indiscriminadamente y con virulencia las legalizaciones, legitimaciones y sanciones para servirse de ellas contra su enemigo interno.

En un Estado que, por el ámbito y las materias que abarcan sus intervenciones, es "totalitario» y que, al mismo tiempo, está desmembrado en un Estado pluralista de partidos, esos fragmentos de poder que se apoderan de la influencia política, tanto si son relativamente duraderos como si tienen una existencia fugaz, están todos sometidos a la misma coacción: la de aprovechar el instante de su poder para anticiparse a su adversario interno y considerar toda especie de justificación como arma para la lucha política interna (Schmitt, 1971, p. 151).

Al diluirse cualquier residuo de autoridad, cuando la legitimidad y la legalidad se convierten en meros instrumentos tácticos de los partidos para ser utilizados como armas contra el otro, Schmitt señala que en vez de ser instrumentos aptos para impedir la guerra civil, sólo contribuyen a exacerbarla. 
Para Schmitt existe una legalidad republicana y es justamente ésta la única forma de legitimidad en el interior del Estado. Pese a todas las limitaciones de la legitimidad plebiscitaria, entre las cuales señala, la imposibilidad del pueblo de asesorarse, deliberar o discutir, Schmitt encuentra que es la única justificación estatal que todavía podía reconocerse como válida dentro del marco de las tendencias que derivaban, como consecuencia de las debilidades del Estado pluralista, hacia el Estado totalitario.

[...] la razón de ser del «Estado totalitario» actual o, más exactamente, de la polítización total de toda la existencia humana, hay que buscarla en la democracia, y que [...] para emprender la necesaria despolitización y librarse del Estado totalitario se necesita una autoridad estable que sea capaz de restablecer esferas y dominios para una vida libre (Schmitt, 1971, p. 146).

Por ello, bien se ha dicho que más que un partidario del Estado, Schmitt buscó el restablecimiento de la política, con sus prerrogativas y límites, para el establecimiento de un orden que garantizase un ámbito de libertad. Fue partidario de la necesidad la expresión de la voluntad inmediata del Pueblo como medio necesario para destrabar las indecisiones parlamentarias que podían llevar al estado de excepción generado por falta de decisión.

Pueblo es un concepto que sólo adquiere existencia en la esfera de lo público. [...] Sólo el pueblo verdaderamente reunido es pueblo, y sólo el pueblo verdaderamente reunido puede hacer lo que específicamente corresponde a la actividad del pueblo: puede aclamar, es decir, expresar por simples gritos su asentimiento o recusación, gritar "viva" o "muera», festejar a un jefe o una proposición, vitorear al rey o cualquier otro, o negar la aclamación con el silencio o murmullos (Schmitt, 1982, p. 238).

\section{Conclusiones}

No está de más resaltar la importancia que ha tenido Schmitt en los países de habla hispana, desde que fue España el país donde encontró refugio varias veces luego del período de la ocupación 
de Alemania. Sin embargo, tal como lo destacamos en la Introducción, hemos preferido efectuar una recopilación de sus notas más importantes para efectuar acercamiento directo al pensador alemán, sin intermediarios ni lecturas provenientes de vertientes nacionalistas ${ }^{5}$.

En una era de las neutralizaciones, el ius publicista alemán ha sido un claro representante de lo político y de su primacía sobre otros fenómenos. Es que ciertamente, la política aunque velada ya sea por la moral, la estética y últimamente por la economía no pierde su esencia.

En este limitado estudio, que supuso un recorte temático y temporal de la obra de Carl Schmitt, podemos advertir que los problemas que señala no han sido superados ni por los actuales modelos teóricos ni por modelos empíricos. Los problemas de legitimidad y legalidad de nuestra Latinoamérica, la neutralización de los político por la tecnocracia impulsados actualmente por la Nueva Gestión Pública; los absolutismos de la democracia que han llevado al Brexit, un (neo)liberalismo que desde "los mercados" sigue minando la autoridad de los Estados, son problemas similares a los que Schmitt denuncia ${ }^{6}$.

Contra las posiciones meramente jurídicas del Estado, Schmitt sostiene que ni la Teoría del Estado de Jellinek ni la Teoría del Derecho puro de Kelsen logran explicar el acto de creación del derecho: el derecho no es producto de consideraciones científicas o mero factum, sino que es - para nuestro autor- decisión como consecuencia de consideraciones sociales en cuanto el Estado está obligado a cumplir sus deberes políticos.

\footnotetext{
${ }^{5}$ Es dable destacar que esta tendencia se está revirtiendo porque, desde el socialismo, sus descripciones de las contradicciones internas de la política liberal brindan ineludibles puntos de partida para el análisis del Estado moderno.

${ }^{6}$ Que no haya continuado, post nacionalsocialismo, con estos temas-problemas, no debe entenderse como un desinterés sino más bien haber advertido que las contradicciones no pueden ser resueltas ni superadas sin un nuevo orden internacional.
} 
Así, la Constitución no deriva de una norma cuya justicia sea fundamento de su validez sino de una decisión política surgida de un Ser político. Tampoco la Constitución constituye a la unidad política, porque aquella es sólo una decisión, esto es, la determinación consciente de la forma concreta que adopta la voluntad de una unidad política ya existente, forma que puede cambiar sin que desaparezca la unidad. Entonces, "la unidad política es representada como un todo. En esa representación hay algo que va más allá de cualquier mandato y de cualquier función" (Schmitt, 1982, p. 211).

Su preocupación estaba en no en retardar la desaparición de una configuración política sino en encontrar otra figura ordenadora sin las ambigüedades de la política liberal. Schmitt, fuera de toda moral liberal, reclamaba el reconocimiento de las prerrogativas del Estado para establecer el valor supremo del orden, no como Estado total, sino como protector de los ciudadanos frente a la amenaza de la guerra civil en lo interior y de la guerra frente al enemigo exterior, prerrogativas éstas que, siguiendo a Hobbes, son éticas.

Si el liberalismo presuponía una coherencia dada entre derecho, legalidad, justicia y libertad, pero en sus propios presupuestos, considera a los representantes del pueblo consagrados a la obtención del bien público, mientras que a su vez, el pueblo es necesariamente el legitimador del sistema ¿por qué la necesidad del control legislativo? En contra del pensamiento liberal, Schmitt sostiene que la experiencia histórica demostraba que una vez adquirido legalmente el poder, nada puede asegurar que se lo ejerza conforme a las normas, ni que las normas que se aprueben no modifiquen el espíritu del sistema establecido. Por ello la experiencia le prueba a Schmitt que el Estado ha debido instaurar controles contra las incoherencias del ámbito legislativo.

La gran decisión se le plantea a Schmitt como una vía dramática: la gran creación del ius publicum europaeum, el Estado, se estaba desmoronado sin que existiese otro nuevo orden capaz de alcanzar sus resultados, esto es, secularización en el ámbito interior como garantía del cese de las luchas religiosas y, en el aspecto exterior, "guerras en forma" entre entidades estatales en igual plano moral. 
¿Qué remedio había previsto el Estado de legalidad parlamentario contra esa posibilidad? Schmitt señalaba la posibilidad de la existencia de un tercero imparcial, guardián de la Constitución, que se convertiría entonces en un tercero superior, supraparlamentario y suprademocrático, no muy lejos del Consejo Nocturno de Las Leyes de Platón.

Ese tercer legislador extraordinario surgía de la facultad del presidente del Reich, ante situaciones extraordinarias, de legislar a través de ordenanzas o medidas jurídicas sustitutivas de las leyes (Constitución de Weimar, art. 48). Podía legislar no sólo prater legem sino también contra legem, sea a través de ordenanzas de carácter general o particular, facultades éstas que le hacen asumir la cualidad de legislador extraordinario ratione tempori ac situacionis. Ese tercero, no sería otro que Hitler a quien, con su diatriba contra el liberalismo, inicialmente apoyó 7 . Pero las facultades extraordinarias ya estaban en la Constitución que tanto criticaba (y que aún siguen estando en tantas otras constituciones).

Muchas veces, relator de los problemas concretos e históricos, pero otras tantas, oráculo de los problemas futuros y sempiternos de la política, este discípulo de Weber merece una relectura desapasionada y sin prejuicios.

\footnotetext{
${ }^{7}$ ¿No había dicha ya en 1927 que el soberano es aquel que toma la decisión apropiada a un estado de excepción? Tal vez Schmitt creyera que Hitler luego de la purga finalizaría la situación de excepción y se restablecería el derecho estatal normal. Lo cierto es que, como comenta Aricó (1984), Schmitt confundió la gran oportunidad de restaurar la política a sus causes con la occasio del nacionalsocialismo de instaurar un gran Leviatán que superara las limitadas formas estatales de la política liberal.
} 


\section{REFERENCIAS}

Aricó, J. (1984). Presentación, Nota Bibliográfica y Bibliografía. En, C. Schmitt (Eds.), El concepto de lo "político (IX-XLII). Buenos Aires: Folios Ediciones.

Mohler, A. (2007). Schmitt y la revolución conservadora. En, J. C. Corbetta y R. S. Piana (Comps.), Política y orden mundial: ensayos sobre Carl Schmitt (101-126). Buenos Aires: Prometeo.

Schmitt, C. (2005). El Nomos de la Tierra en el Derecho de Gentes del "Jus publicum europaeum". Buenos Aires: Struhart \& Cía.

Schmitt, C. (1984). El concepto de lo "político". Teoría del partisano. Notas complementarias al concepto de lo "político". Buenos Aires: Folios Ediciones.

Schmitt, C. (1982). Teoría de la Constitución. Madrid: Alianza.

Schmitt, C. (1971). Legalidad y Legitimidad. Madrid: Aguilar.

Schmitt, C. (1968). La dictadura. Desde los comienzos del pensamiento moderno de la soberanía hasta la lucha de clases proletaria. Madrid: Revista de Occidente. 
Ricardo Sebastián Piana es Doctor en Ciencia Política de la Universidad del Salvador - USAL (Argentina) y Doctor en Ciencias Jurídicas de la Universidad Nacional de La Plata - UNLP (Argentina). Titular de la materia Derecho Político y Teoría y Derecho Constitucional de la USAL (Argentina) y Adjunto a Derecho Político de la UNLP (Argentina). Titular Seminario de Investigación en la Universidad Católica de La Plata - UCALP (Argentina).

* Informe de Investigación del Seminario de Teoría Política dirigido por el Dr. Carlos Fernández Pardo, correspondiente al Doctorado en Ciencia Política de la Universidad del Salvador (Argentina). 